\title{
Study of possible Cardioprotective Effect of Hydroxychloroquine Compared to Glimepiride and Metformin in Diabetic Rats
}

Heba A. EL noury ${ }^{a}$, Ahmed F. Bahriz ${ }^{\text {, }}$, Amany N. Ibrahim ${ }^{a}$, Aya M. El-Badrawy ${ }^{\text {, }}$ Eman A. Abd El Aziz ${ }^{\text {a }}$

a Department $\begin{array}{r}\text { of } \\ \text { pharmacology, Benha faculty } \\ \text { of medicine, }\end{array}$ Banha
University,
b Department of Clinical
Pharmacology, Faculty of
medicine, kafr El-sheikh
University.
Correspondence to: Aya
M. El-Badrawy, Department
of Clinical Pharmacology,
Faculty of medicine, kafr El-
sheikh University.

Email:

dr_aya_sky@yahoo.com

Received: 22 September 2021

Accepted: 5 December 2021

\begin{abstract}
:
Background: Diabetes is associated with both micro- and macrovascular complications. Aim of the study: The aim of the present study is to evaluate the prophylactic effect of HCQ alone and in combination with glimepiride and metformin on ISO induced MI in type 2 diabetic rats. The present study included the parameters blood glucose, plasma insulin, HOMA-IR index, lipid profile, AKT, ECG changes and histopathology of the myocardium. Methods: Rats were classified into: Group I: control normal group. Group II: was not treated diabetic (diseased group). Group III: was treated with HCQ. Group IV: was treated with glimepiride. Group V: was treated with metformin. Group VI: was treated with HCQ + glimepiride. Group VII: was treated with HCQ + metformin. treated groups received drugs for 4 weeks. Results: Treated groups showed significant improvement in all parameters and improvement of the histopathology of the myocardium. A significant improvement in the parameters was seen in the treated groups at the end of the $4^{\text {th }}$
\end{abstract} week. Conclusion: Our study revealed that HCQ with glimepiride or with metformin produced more improvement in blood glucose level, insulin, HOMA-IR, lipid profile, AKT, ECG changes, histopathology of the myocardium. So, our drugs, mainly combined drugs may have a prophylactic effect against MI in diabetic rats. this may be due to their glycemic control and improvement of dyslipidemia.

Key words: diabetes mellitus, myocardial infarction, HCQ, Glimepiride, metformin.

Abbreviations: HCQ; Hydroxychloroquine, Isoprenaline; ISO, MI; Myocardial infarction, AKT; protein kinase B. 


\section{Introduction}

Diabetes mellitus (DM) was defined by The American Diabetes Association (ADA) as a group of metabolic diseases characterized by hyperglycemia resulting from defects in insulin secretion, insulin action or both. The chronic hyperglycemia of diabetes is associated with long-term damage, dysfunction and failure of different organs, especially the eyes, kidneys, nerves, heart and blood vessels [1]. People with type 2 diabetes mellitus (T2DM) are at increased risk of cardiovascular disease, heart failure and death, as compared with the general population. In the last two decades, several studies have demonstrated reductions in the risk of cardiovascular outcomes and mortality in patients with T2DM with improved glucose and cholesterol-lowering therapies [2]. Nevertheless, macrovascular disease remains the most common cause of death in T2DM patients and new diabetes therapies are highly desired, especially if they can offer cardiovascular benefits [3].

Hydroxychloroquine (HCQ) has been widely used as DMARD either alone or in combination with other DMARDs. HCQ has been reported to have pleiotropic effects, including metabolic profile improvement, anti- oxidant, anti-aggregation and antithrombotic effects [4]. Glimepiride, an insulin secretagogue lowers hyperglycemia by stimulating insulin release [5].

Metformin, the most widely used oral antihyperglycemic agent, is currently recommended as first line therapy for all newly diagnosed diabetes T2DM patients which acts mainly as an insulin sensitizer [1].

\section{Materials and method}

This study was a clinical trial; it was conducted during the period from July 2020 to January 2021.

\section{Animals:}

Eighty-four adult male albino rats obtained from (Experimental Animal Breeding Farm, Helwan-Cairo) weighing between 150- 200 g were used for in-vivo experiments. They were acclimatized for one week and were caged (4 rat/ cage) in fully ventilated room at room temperature in the pharmacology department, Benha Faculty of Medicine. Rats were fed a standard chow with water. 
This study was approved from ethical committee of Benha Faculty of Medicine.

\section{Drugs}

Hydroxychloroquine sulphate (SANOFI, Egypt), Glimepiride (SANOFI, Egypt), Metformin (Cid), Urethane (Ethyl carbamate): (prolabo, Paris). Isoprenaline (Sigma CO., USA. The biochemical analysis was performed using standard kits. The chemicals used in this study were all of high analytical grade.

\section{Experimental groups and procedures:}

The rats were classified into 7 equal groups $(\mathrm{n}=12)$ as follow;

(GI) Normal Control group.

(GII) Non treated diabetic rats: diabetes was induced by administration of $20 \%$ fructose solution in drinking water for 2 weeks. Then intra peritoneal injection of a low dose STZ (40 mg/kg b.w.) [6,7].

(GIII) HCQ treated diabetic group: HCQ was administered at a dose of $160 \mathrm{mg} / \mathrm{kg}$ /day P.O. [8,9].

GIV glimepiride treated diabetic group: glimepiride was administered at a dose of 0.5 $\mathrm{mg} / \mathrm{kg}$ /day P.O. [10].

(GV) Metformin treated diabetic group; metformin was administered at a dose of $100 \mathrm{mg} / \mathrm{kg} /$ day P.O. [11].
(GVI) HCQ+glimepiride treated diabetic group.

(GVII) HCQ+metformin treated diabetic group. The treated groups received the tested drugs for 4 weeks then myocardial infarction was induced in all diabetic groups by injection of isoprenaline (ISO) $(150 \mathrm{mg} / \mathrm{kg}$ S.C) [12].

At the end of the experiment, the animals were anesthetized with Urethane [13], then ECG was done 2 hours after injection of ISO.

After ECG recording, the chest was then rapidly opened and blood sample about $(3 \mathrm{ml})$ was collected from the right ventricle before removal of the heart from chest. Blood samples were incubated at $37^{\circ} \mathrm{C}$ until clotting, and then centrifuged at 3000 revolution per minute (rpm) for 15 minutes, for separation of serum and stored at $-20^{\circ} \mathrm{C}$ for biochemical analysis of blood glucose, plasma insulin, HOMA-IR index and lipid profile. A weight of $30 \mathrm{mg}$ of frozen heart tissue was grinded into liquid nitrogen at $80^{\circ} \mathrm{c}$ until use. The heart was kept in formaldehyde to be stained with Hematoxylin and Eosin.

\section{Measurement of blood glucose:}

By GOD-PAP enzymatic colorimetric method [14].

\section{Measurement of insulin:}


By rat-specific enzyme immunoassay [15].

\section{Measurement of HOMA-IR index:}

Insulin resistance was measured using the homeostasis model assessment of insulin resistance (HOMA IR index) [16].

HOMA- IR $=\frac{\text { Fasting blood glucose }(\mathrm{mg} / \mathrm{dl}) \text { } X \text { Fasting plasma insulin }(\mu \mathrm{\mu u} / \mathrm{ml})}{405}$

\section{Measurement of serum lipid profile:}

- Cholesterol (TC) and triglycerides (TG): This was carried out by "Enzymatic colorimetric test",[17] Respectively. HDLcholesterol: This is carried out by "separation of high-density lipoproteins (HDL) and determination of cholesterol bound to these fractions"[18]. LDL-cholesterol $=$ Total Cholesterol-(HDL-cholesterol+ $\quad$ TG/5) (mg/dl) [19].

\section{Protein kinase B assay (AKT level) by real time PCR}

This assay employs the quantitative sandwich enzyme immunoassay technique [20].

\section{Histopathological examination of the myocardium}

Transverse sections (2mm thickness) of the left ventricle free wall at the papillary muscle level were stained with hematoxylin and eosin then cardiac sections were examined for the presence of myocyte degenerative changes and infarction like necrosis [21]. Normal architecture of myocardium with intact cardiomyocytes shown in Figure 1.

\section{Statistical analysis:}

The collected data were summarized in terms of mean \pm Standard Deviation (SD). Comparisons between the different study groups were carried out using the one-way analysis of variance (ANOVA) followed by post hoc tests using the LSD method using the Statistical Package for Social Science (SPSS) program, version 19(Chicago IL USA, 2000). $P$-value $<0.05$ was considered statistically significant.

\section{Results}

Induction of DM by HF-STZ (high fructose + streptozotocin) resulted in significant increase in blood glucose, insulin level and HOMA IR index, total cholesterol, LDL, triglycerides with significant decrease in HDL levels. In singly treated groups there was significant improvement in all previously mentioned parameters. There was insignificant difference between metformin and glimepiride diabetic treated regarding to FBG while metformin was more effective in decreasing insulin level and HOMA IR index than glimepiride and Hydroxychloroquine respectively. Combination groups showed more 
significant improvement of plasma insulin level and HOMA IR index compared to singly treated groups with normalization of FBG level (table1). Moreover, administration of metformin alone or in combination with Hydroxychloroquine resulted in normalization of lipid profile. Also, Hydroxychloroquine + glimepiride treated group showed normalization of lipid profile except for HDL level still significantly lower than normal control group (table 2).

Induction of MI by isoprenaline on top of diabetes resulted in significant increase in
HR, ST-segment elevation and AKT level (table3), this was accompanied with histopathological cardiac injury in the form of degeneration and necrosis of cardiomyocytes with infiltration of inflammatory cells (figure 2). Administration of the tested drugs singly resulted in significant improvement of HR, ST-segment elevation and AKT level with improvement of histopathological myocardial changes compared to non-treated group (figure $\mathbf{3 , 4 , 5}$ ) while combination groups were more effective (figure 6,7).

Table (1) Effect of treatment with hydroxychloroquine, Glimepiride, Metformin, (hydroxychloroquine + glimepiride) and (hydroxychloroquine + metformin) on (FBG, FPI, HOMA-IR) on experimentally induced diabetes in rats:

\begin{tabular}{|c|c|c|c|}
\hline & $\begin{array}{l}\text { blood glucose } \\
\text { (mg/dl) }\end{array}$ & $\begin{array}{l}\text { Serum insulin } \\
(\mu \mathrm{IU} / \mathrm{ml})\end{array}$ & $\begin{array}{l}\text { HOMA IR } \\
\text { Index }\end{array}$ \\
\hline Normal control (GI) & $83.33 \pm 3.51$ & $31.94 \pm 4.69$ & $6.58 \pm 1.22$ \\
\hline $\begin{array}{l}\text { Non - treated diabetes infarcted } \\
\text { group (G II) }\end{array}$ & $307.33 \pm 25.42^{\mathrm{a}}$ & $120.37 \pm 4.27^{\mathrm{a}}$ & $91.16 \pm 4.36^{\mathrm{a}}$ \\
\hline $\begin{array}{l}\text { Hydroxychloroquine treated } \\
\text { group (GIII) }\end{array}$ & $\begin{array}{l}243.00 \pm 13.75^{\mathrm{a}, \mathrm{b}} \\
* \downarrow 20.93 \%\end{array}$ & $\begin{array}{l}109.68 \pm 2.36^{\mathrm{a}, \mathrm{b}} \\
* \downarrow 8.88 \%\end{array}$ & $\begin{array}{l}65.75 \pm 2.52^{a, b} \\
* \downarrow 27.87 \%\end{array}$ \\
\hline $\begin{array}{l}\text { Glimepiride treated group } \\
\text { (G IV) }\end{array}$ & $\begin{array}{l}130.33 \pm 11.02^{\text {a,b.c }} \\
* \downarrow 57.59 \%\end{array}$ & $\begin{array}{l}101.90 \pm 8.47^{\mathrm{a}, \mathrm{b}, \mathrm{c}} \\
* \downarrow 15.34 \%\end{array}$ & $\begin{array}{l}32.64 \pm 1.10^{\mathrm{a}, \mathrm{b}, \mathrm{c}} \\
* \downarrow 64.19 \%\end{array}$ \\
\hline $\begin{array}{l}\text { Metformin treated group } \\
(\mathrm{G} \mathrm{V})\end{array}$ & $\begin{array}{l}143.00 \pm 12.53^{\mathrm{a}, \mathrm{b}, \mathrm{c}} \\
* \downarrow 53.47 \%\end{array}$ & $\begin{array}{l}72.34 \pm 4.51^{\mathrm{a}, \mathrm{b}, \mathrm{c}, \mathrm{d}} \\
* \downarrow 39.90 \%\end{array}$ & $\begin{array}{l}25.49 \pm 2.04^{\mathrm{a}, \mathrm{b}, \mathrm{c}, \mathrm{d}} \\
* \downarrow 72.03 \%\end{array}$ \\
\hline $\begin{array}{l}\text { Hydroxychloroquine }+ \text { glimepiride treated } \\
\text { group }(\mathrm{G} \mathrm{VI})\end{array}$ & $\begin{array}{l}79.67 \pm 4.51^{\mathrm{b}, \mathrm{c}, \mathrm{d}, \mathrm{e}} \\
* \downarrow 74.07 \%\end{array}$ & $\begin{array}{l}57.26 \pm 5.67^{\mathrm{a}, \mathrm{b}, \mathrm{c}, \mathrm{d}, \mathrm{e}} \\
* \downarrow 52.43 \%\end{array}$ & $\begin{array}{l}11.29 \pm 1.60^{\mathrm{a}, \mathrm{b}, \mathrm{c}, \mathrm{d}, \mathrm{e}} \\
* \downarrow 87.61 \%\end{array}$ \\
\hline $\begin{array}{l}\text { Hydroxychloroquine }+ \text { metformin treated } \\
\text { group (G VII) }\end{array}$ & $\begin{array}{l}88.00 \pm 3.61^{\mathrm{b}, \mathrm{c}, \mathrm{d}, \mathrm{e}} \\
* \downarrow 71.36 \%\end{array}$ & $\begin{array}{l}45.33 \pm 1.5^{\text {a,b,c,d,e.f }} \\
* \downarrow 62.34 \%\end{array}$ & $\begin{array}{l}9.83 \pm 0.29^{\mathrm{a}, \mathrm{b}, \mathrm{c}, \mathrm{d}, \mathrm{e}} \\
* \downarrow 89.21 \%\end{array}$ \\
\hline
\end{tabular}

a: Significant versus control (G1).

b: Significant versus diseased group (G2).

c: Significant versus Hydroxychloroquine group (G3).

d: Significant versus Glimepiride group (G4).

e: Significant versus metformin group (G5). 
f: Significant versus hydroxychloroquine + Glimepiride group (G6).

*: \% change was calculated in relation to non-treated diabetes infarcted group $(\mathrm{G} 2)$.

Table (2): Effect of treatment with hydroxychloroquine, Glimepiride, Metformin, (hydroxychloroquine + glimepiride) and (hydroxychloroquine + metformin) on (total cholesterol, LDL, triglycerides and HDL) on experimentally induced diabetes in rats:

\begin{tabular}{|c|c|c|c|c|}
\hline & $\begin{array}{l}\text { Total cholesterol } \\
\text { mg/dl }\end{array}$ & $\begin{array}{l}\text { Triglycerides } \\
\text { mg/dl }\end{array}$ & $\begin{array}{l}\text { LDL-C } \\
\mathrm{mg} / \mathrm{dl}\end{array}$ & $\begin{array}{l}\text { HDL-C } \\
\mathrm{mg} / \mathrm{dl}\end{array}$ \\
\hline Normal control (GI) & $116.00 \pm 4.58$ & $119.67 \pm 11.59$ & $37.40 \pm 6.32$ & $54.67 \pm 2.52$ \\
\hline $\begin{array}{l}\text { Hydroxychloroquine treated } \\
\text { group (G III) }\end{array}$ & $\begin{array}{l}195.33 \pm 9.61^{\mathrm{a}, \mathrm{b}} \\
* \downarrow 17.92 \%\end{array}$ & $\begin{array}{l}163.67 \pm 13.87^{\mathrm{a}, \mathrm{b}} \\
* \downarrow 25.15 \%\end{array}$ & $\begin{array}{l}119.30 \pm 14.10^{\mathrm{a}, \mathrm{b}} \\
* \downarrow 23.67 \%\end{array}$ & $\begin{array}{l}43.33 \pm 3.21^{\mathrm{a}, \mathrm{b}} \\
* \uparrow 14.02 \%\end{array}$ \\
\hline $\begin{array}{l}\text { Glimepiride treated group } \\
\text { (G IV) }\end{array}$ & $\begin{array}{l}131.33 \pm 13.43^{\mathrm{b}, \mathrm{c}} \\
* \downarrow 44.81 \%\end{array}$ & $\begin{array}{l}133.67 \pm 14.57^{\mathrm{b}, \mathrm{c}} \\
* \downarrow 38.87 \%\end{array}$ & $\begin{array}{l}57.30 \pm 8.60^{\mathrm{a}, \mathrm{b}, \mathrm{c}} \\
* \downarrow 63.33 \%\end{array}$ & $\begin{array}{l}47.33 \pm 2.08^{\mathrm{a}, \mathrm{b}, \mathrm{c}} \\
* \uparrow 24.55 \%\end{array}$ \\
\hline $\begin{array}{l}\text { Metformin treated group } \\
(\mathrm{G} \mathrm{V})\end{array}$ & $\begin{array}{l}125.00 \pm 13.45^{\mathrm{b}, \mathrm{c}} \\
* \downarrow 47.47 \%\end{array}$ & $\begin{array}{l}125.00 \pm 9.85^{\mathrm{b}, \mathrm{c}} \\
* \downarrow 42.83 \%\end{array}$ & $\begin{array}{l}48.70 \pm 7.04^{\mathrm{bc}, \mathrm{d}} \\
* \downarrow 68.84 \%\end{array}$ & $\begin{array}{l}51.33 \pm 1.53^{\mathrm{b}, \mathrm{c}} \\
* \uparrow 35.07 \%\end{array}$ \\
\hline
\end{tabular}

Data were presented as mean $\pm \mathrm{SD},(\mathrm{P}<0.05)$

a: Significant versus control (G1).

b: Significant versus diseased group $(\mathrm{G} 2)$.

c: Significant versus Hydroxychloroquine group (G3).

d: Significant versus Glimepiride group (G4).

e: Significant versus metformin group (G5).

f: Significant versus hydroxychloroquine + Glimepiride group (G6).

*: \% change was calculated in relation to non-treated diabetes infarcted group (G 2). 
Table (3). Effect of treatment with hydroxychloroquine, Glimepiride, Metformin, (hydroxychloroquine + glimepiride) and (hydroxychloroquine + metformin) on (heart rate, ST segment elevation \& AKT) on experimentally induced myocardial infarction in diabetic rats.

\begin{tabular}{|c|c|c|c|}
\hline & $\begin{array}{l}\text { HR } \\
(\mathbf{b} / \mathbf{m})\end{array}$ & $\begin{array}{l}\text { ST segment } \\
\text { Elevation (mv) }\end{array}$ & AKT \\
\hline Normal control (GI) & $302 \pm 38.71$ & 0 & $1.00 \pm 0.85$ \\
\hline $\begin{array}{l}\text { Non - treated diabetes infarcted } \\
\text { group (G II) }\end{array}$ & $530 \pm 99.00^{\mathrm{a}}$ & $2.72 \pm 0.26^{\mathrm{a}}$ & $8.75 \pm 0.04^{\mathrm{a}}$ \\
\hline Hydroxychloroquine treated & $441 \pm 67.76^{\mathrm{a}, \mathrm{b}}$ & $1.46 \pm 0.27^{\mathrm{a}, \mathrm{b}}$ & $5.46 \pm 0.35^{\mathbf{a}, \mathbf{b}}$ \\
\hline group (GII) & $* \downarrow 16.79 \%$ & $* \downarrow 46.32 \%$ & $* \downarrow 37.6 \%$ \\
\hline Glimepiride treated group & $371 \pm 5.90^{\mathrm{a}, \mathrm{b}}$ & $1.36 \pm 0.22^{\mathrm{a}, \mathrm{b}}$ & $3.82 \pm 0.12^{\mathbf{a , b}, \mathbf{b}}$ \\
\hline (G IV) & $* \downarrow 30 \%$ & $* \downarrow 50 \%$ & $* \downarrow 56.34 \%$ \\
\hline Metformin treated group & $376 \pm 89.72^{a, b}$ & $1.45 \pm 0.27^{\mathrm{a}, \mathrm{b}}$ & $2.91 \pm 0.19^{\mathbf{a , b , c , d}}$ \\
\hline$(\mathrm{G} \mathrm{V})$ & $* \downarrow 29.05 \%$ & $* \downarrow 46.69 \%$ & $* \downarrow 66.74 \%$ \\
\hline Hydroxychloroquine + glimepiride & $336 \pm 44.55^{\mathrm{a}, \mathrm{b}, \mathrm{c}, \mathrm{d}, \mathrm{e}}$ & $0.91 \pm 0.10^{\mathrm{a}, \mathrm{b}, \mathrm{c}, \mathrm{d}, \mathrm{e}}$ & $1.95 \pm 0.46^{\text {a,b.c.,d,e }}$ \\
\hline treated group (G VI) & $* \downarrow 36.6 \%$ & $* \downarrow 66.54 \%$ & $* \downarrow 77.71 \%$ \\
\hline Hydroxychloroquine +metformin & $331 \pm 38.44^{\mathrm{a}, \mathrm{b}, \mathrm{c}, \mathrm{d}, \mathrm{e}}$ & $0.90 \pm 0.14^{\mathrm{a}, \mathrm{b}, \mathrm{c}, \mathrm{d}, \mathrm{e}}$ & $1.62 \pm 0.15^{\mathbf{a , b}, \mathbf{c}, \mathbf{d}, \mathbf{e}}$ \\
\hline treated group (GVII) & $* \downarrow 37.54 \%$ & $* \downarrow 66.91 \%$ & $* \downarrow 81.48 \%$ \\
\hline
\end{tabular}

Data were presented as mean $\pm \mathrm{SD},(\mathrm{P}<0.05)$

a: Significant versus control (G1).

b: Significant versus diseased group (G2).

c: Significant versus Hydroxychloroquine group (G3).

d: Significant versus Glimepiride group (G4).

e: Significant versus metformin group (G5).

f: Significant versus hydroxychloroquine + Glimepiride group (G6).

*: \% change was calculated in relation to non-treated diabetes infarcted group (G 2). 


\section{Histopathological changes:}
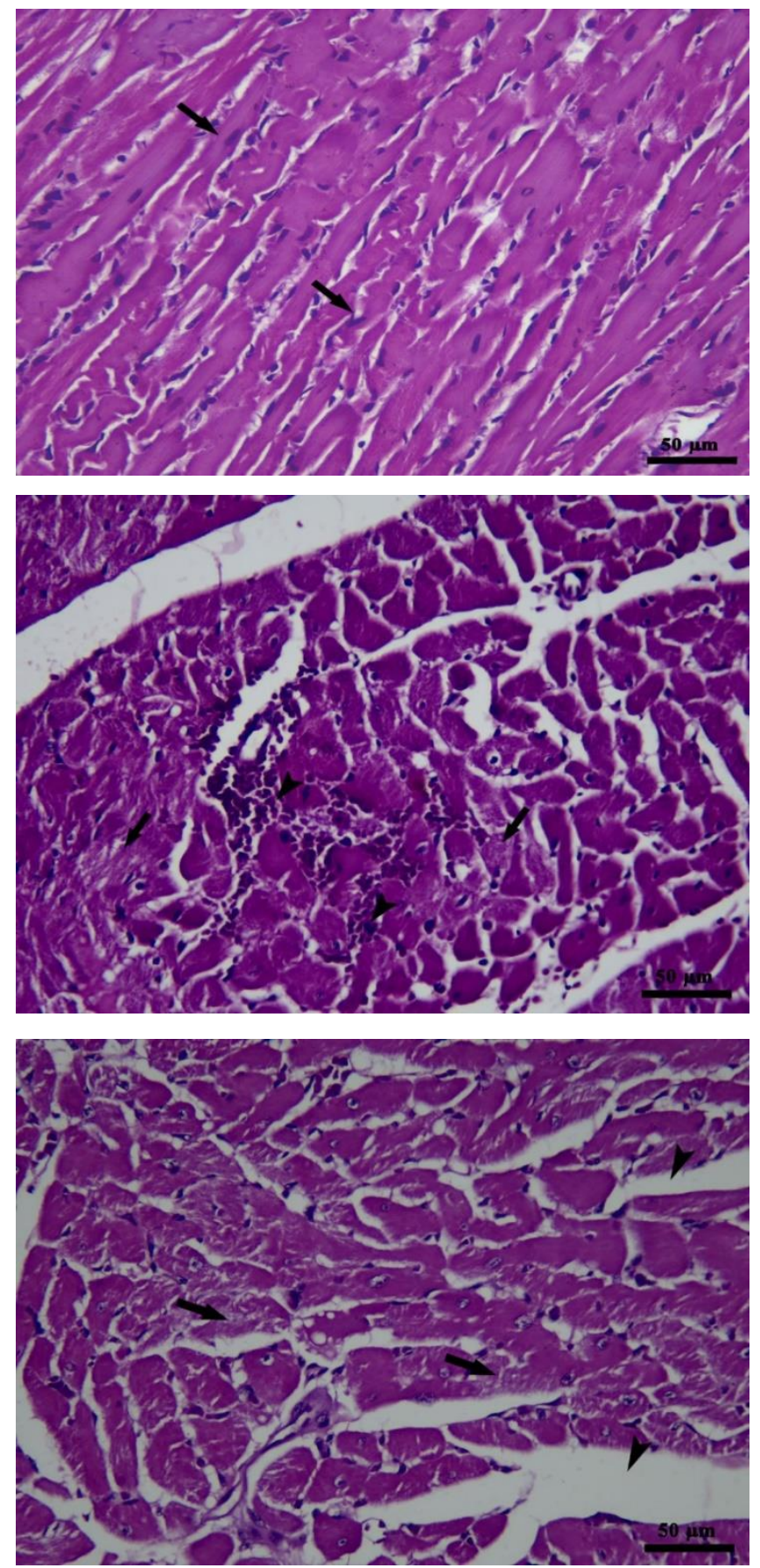

Fig. 1: photomicrograph of heart of G1 showing normal architecture of myocardium with intact cardiomyocytes (arrows). H\&E, bar $=50 \mu \mathrm{m}$.

Fig. 2: photomicrograph of heart of G2 showing areas of degeneration and necrosis of cardiomyocytes (arrows) with infiltration of inflammatory cells (arrow heads). H\&E, bar $=50 \mu \mathrm{m}$.

Fig. 3: photomicrograph of heart of G3 showing areas of vacuolar degeneration and necrosis of cardiomyocytes (arrows) with edema (arrow heads) and loss of myocardium architecture. $\mathrm{H} \& \mathrm{E}$, bar $=50 \mu \mathrm{m}$. 

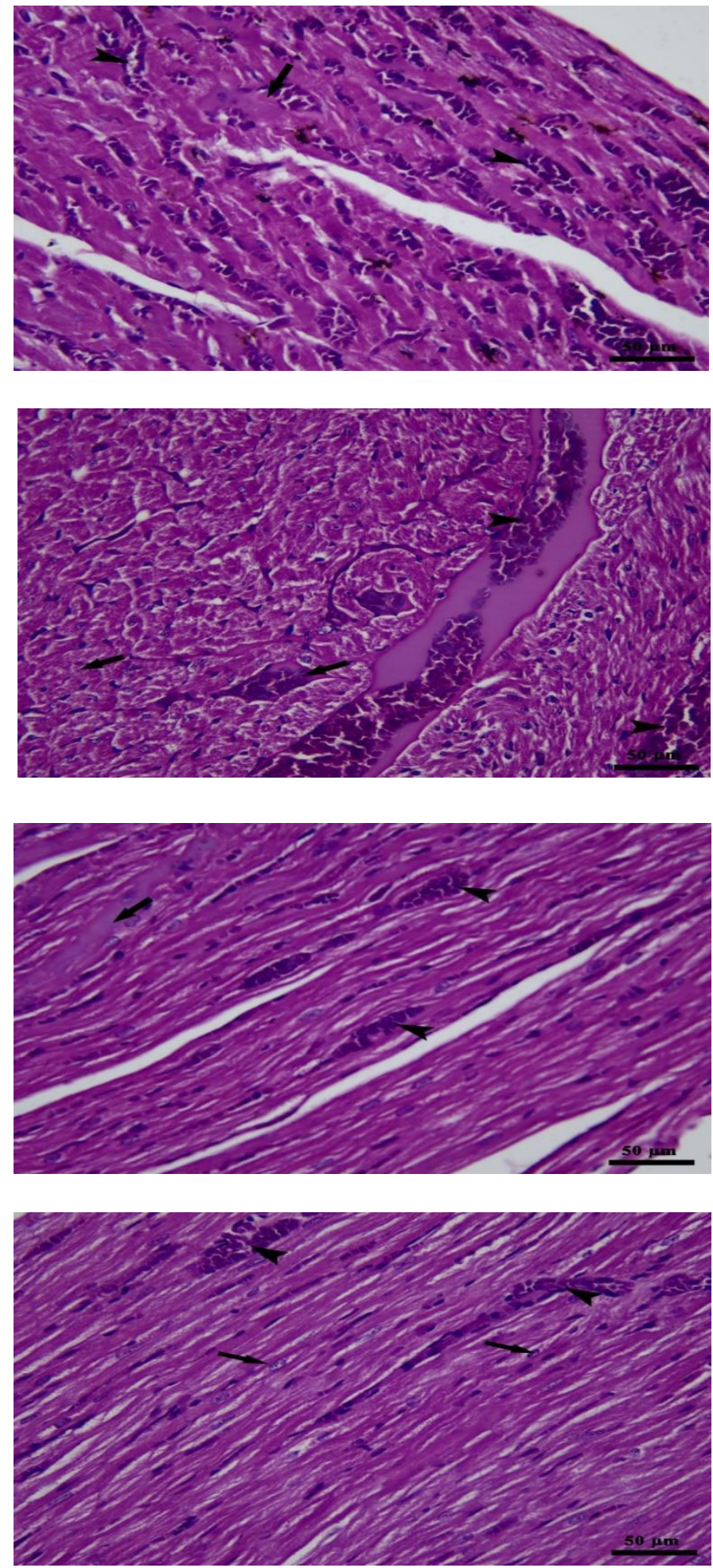

Fig.4: photomicrograph of heart of G4 showing small area of degeneration and necrosis of myocardial cells (arrow) with congestion of cardiac blood vessels (arrow heads). H\&E, bar $=50 \mu \mathrm{m}$.

Fig. 5: photomicrograph of heart of G5 showing moderate degeneration and necrosis of cardiomyocytes (arrows) with congestion of blood vessels and infiltration of inflammatory cells (arrow heads). H\&E, bar $=50 \mu \mathrm{m}$.

Fig.6: photomicrograph of heart of G6 showing mild degree of degeneration of cardiomyocytes (arrows) with mild congestion of blood vessels (arrow heads). H\&E, bar $=50 \mu \mathrm{m}$.

Fig. 7: photomicrograph of heart of G7 showing intact myocardial cells (arrows) with mild congestion of some blood vessels and infiltration of inflammatory cells (arrowheads). H\&E, bar=50 $\mu \mathrm{m}$. 


\section{Discussion}

The present study was designed to evaluate the effect of hydroxychloroquine, glimepiride, metformin and their combinations on experimentally-induced myocardial infarction in diabetic rats regarding to their effect on blood glucose, insulin, insulin resistance, lipid profile, and histopathology of the heart .as well as heart rate, ST segment elevation, protein kinase $\mathrm{B}$ level (AKT).

In the current work T2DM was achieved by administration of $20 \%$ fructose solution in drinking water for 2 weeks. Then intra peritoneal injection of a low dose STZ (40 $\mathrm{mg} / \mathrm{kg}$ b.w.) $[6,7]$.

Induction of diabetes in rats by fructose and STZ resulted in significant increases in blood glucose, insulin, insulin resistance, TC, LDL, triglyceride and significant decrease in HDL.

These finding were in agreement with several studies [22,23] which reported that HFSTZ-induced T2D was associated with significant increases in blood glucose, urea, creatinine, TC, LDL, triglyceride and significant decrease in HDL.

Treatment with HCQ $160 \mathrm{mg} / \mathrm{kg} /$ day orally, Glimepiride $0.5 \mathrm{mg} / \mathrm{kg} /$ day orally, Metformin 100mg/kg/day orally, HCQ + glimepiride and HCQ + metformin in diabetic rats for 4 weeks resulted in significant improvement insulin resistance parameters namely, fasting blood glucose, serum insulin, HOMA-IR, TC, LDL, triglyceride and HDL level compared to non-treated HF-STZ induced type 2 diabetic group. Combined drugs were superior to single drugs. In supporting with our findings, another study, [24] discussed the efficacy of combined HCQ with glimepiride or with metformin versus each drug alone, reported that HCQ as an adjunct to glimepiride or metformin leads to reducing fasting plasma glucose, insulin, uric acid and increasing high-density lipoprotein cholesterol.

Also, another researchers [25] reported that compared to monotherapy, a combination of HCQ with oral antihyperglycemic drugs (metformin and sulfonylurea) significantly decreased blood glucose level and improved lipid profile, Improved insulin sensitivity and insulin response.

Lipid profile is a strong determinant of cardiovascular risk in T2DM. Current guidelines recommend an accurate control of hypercholesterolemia in order to reduce macrovascular complications. The fact that 
type 2 diabetic patients are more likely to be dyslipidemic than the general population is well known for decades. Lipid abnormalities associated with T2DM refer to high serum triglyceride levels, a high proportion of LDL particles, higher triglyceride-enriched, VLDL particles, and lower protective HDL levels, together with glycation of apolipoproteins and increased LDL oxidation, all of which contribute to genesis of foam cell in atherosclerosis. Atherosclerosis was the major cause of morbidity and mortality in patients with T2DM [26].

Regarding to lipid profile, there was no significant difference between metformin, $\mathrm{HCQ}+$ glimepiride and HCQ + metformin treated groups in cholesterol, TG and LDL parameters of lipid profile. Moreover, there was no significant difference between them and the control group regarding to their effect on cholesterol, TG and LDL. Also, their effect on lipid profile was superior to the effect of HCQ alone. Regarding HDL, there was significant increase in treated groups. There was no significant difference between glimepiride and glimepiride + HCQ treated groups. Moreover, there was no significant difference between HCQ + metformin and the control group regarding to their effect on HDL. So, HCQ + metformin effect on HDL was superior to the effect of other drugs.
The effect of our drugs on lipid profile were consistent that marked improvement and significant reduction in lipid profile with HCQ [27].

A previous study indicated that the effects of explained efficacy of HCQ added to inadequately controlled T2DM with glimepiride and metformin which resulted in combination efficacy in lowering lipid profile [28].

These data were in agreement with Pareek et al. [29] who Considered that the multifaceted effects of HCQ can improve the cardiovascular risk profile in diabetes patients with its favorable actions on blood glucose, lipid profile (fall in TC and LDL-C) and antithrombotic properties, making it an attractive therapeutic choice for the treatment of T2DM patients when compared to pioglitazone and was safe and well tolerated.

Previous evidence indicated that induction of myocardial infarction in diabetic rats resulted in significant elevation "expression" of PKB/AKT level as $\mathrm{PI} 3 \mathrm{~K} / \mathrm{AKT}$ pathway works as an upstream signaling route to stimulate GLUT4 translocation to the cell surface in cardiomyocytes, thereby promoting glucose uptake [30]. 
Also, previous study indicated that [31] the insulin shortage and insulin resistance and T2DM lead to suppression of PI3K/AKT signaling which consequently led to cardiac dysfunction. However, promoting the activation of PI3K/AKT can improve cardiac function.

The results of AKT agreed with Infante et al. [32] who mentioned that a rat model of insulin resistance demonstrated that HCQ can promote insulin-mediated glucose uptake and glycogen synthase activity by activating AKT.

Also, previous studies [33] founded that the increased insulin/IGF-1 resulted in activation of downstream AKT/mTOR cellular survival pathway. These results suggest that HCQ could be a novel and readily translational pharmacotherapy for reducing cardiovascular risk factors and protecting against myocardial $\mathrm{I} / \mathrm{R}$ injury in T2DM.

In addition, Hausenloy et al. [34] reported that glimepiride produced significant reduction in AKT level expression.

The data of the present work revealed that, with respect to the control group, induction of acute myocardial infarction by isoprenaline in diabetic rats resulted in significant increases in heart rate, ST segment. These data were in agreement with, several studies. $[35,36]$

ECG monitoring of isoprenaline-injected rats showed positive $\mathrm{T}$ wave and $\mathrm{ST}$ segment elevation that reflect the isoprenaline-induced myocardial ischemia and infarction. ECG pattern alterations by isoprenaline were in agreement with the previous studies. [35,36] Histopathological examination of cardiac tissue in the ISO-injected group revealed significant increase in histopathological cardiac injury score when compared to the control group, with evident dilatation in coronary blood vessel with thrombus, area of necrosis, sever hydropic degeneration and inflammatory cellular infiltrate with interstitial edema. These data were in agreement with previous studies which reported that ISO-induced MI contributed to cause inflammatory cellular infiltrate with interstitial edema led to degeneration of cardiac myocytes and dilatation of blood vessels with thrombus formation [37]. These observations along with biochemical changes in cardiac enzymes and cytokines confirm the severity of myocardial injury.

Our research revealed that HCQ 160 $\mathrm{mg} / \mathrm{kg} /$ day orally, Glimepiride $0.5 \mathrm{mg} / \mathrm{kg} /$ day orally, Metformin 100mg/kg/day orally, HCQ + glimepiride and HCQ + metformin in diabetic rats for 4 weeks before induction of 
MI restored the near normal ECG pattern with significant decrease in cardiac histopathological injury score when compared to the MI group with improvement of histopathological finding in the form of mild hydropic degeneration without necrotic changes or cellular infiltration. combined groups produced more improvement in, ECG changes and decreasing the infarct size.

These findings were in agreement with several studies [38] which reported that treatment by Three drugs and their combinations before induction of MI significantly decrease the infarct size and ST segment height. In supporting to our findings, a previous study [39] reported that in patients with T2DM and coronary artery disease, treatment with HCQ resulted in a significantly lower rate of progression of coronary atherosclerosis compared with conventional treatment.

\section{Conclusion}

Our study revealed that combined drugs $\mathrm{HCQ}+$ glimepiride or metformin produced more improvement in blood glucose level, insulin, HOMA-IR, AKT and there was no significant difference between them and glimepiride or metformin alone in improving lipid profile but combined HCQ+ metformin was superior in increasing HDL level. So, hydroxychloroquine produced good glycemic control and improved dyslipidemia so, it had a prophylactic effect on the heart.

\section{References}

1.American Diabetes Association (2014): Diagnosis and classification of diabetes mellitus. Diabetes Care 37(Suppl. 1):S81-90. 10.2337/dc14-S081

2.Holman R, Paul S, Bethel M, Matthews D, Neil H(2008): 10-year follow-up of intensive glucose control in type 2 diabetes. $N$ Engl J Med. 2008;359:1577-1589.

3.Rawshani A, Rawshani A, Franzén S, Eliasson B, Svensson A, Miftaraj M(2017): Mortality and cardiovascular disease in type 1 and type 2 diabetes. N Engl J Med. 2017;376:1407-1418.

4. Hidayat, R. (2019). The effect of hydroxychloroquine on endothelial dysfunction in patients with rheumatoid arthritis: A double- blind randomized clinical trial. 14, 59-64.

5. Nissen, S. E., Nicholls, S. J., Wolski, K., Nesto, R., Kupfer, S., Perez, A., et al. (2008). Comparison of pioglitazone vs glimepiride on progression of coronary atherosclerosis in patients with type 2 diabetes: the PERISCOPE randomized controlled trial. Jama, 299(13), 1561-1573.

6.Wilson, R. D., \& Islam, M. S. (2012): Fructosefed streptozotocin-injected rat: an alternative model for type 2 diabetes. Pharmacological Reports, 64(1), 129-139.

7.Okolie, A. C., Kale, O. E., \& Osilesi, O. (2019): Chemoprotective effects of butanol fraction of Buchholzia coriacea (Capparidaceae) against type 2 diabetes and oxidative stress in male Wistar rats. Bioscience reports, 39(2).

8.Emami, J., Gerstein, H. C., Pasutto, F. M., \& Jamali, F. (1999). Insulin-sparing effect of hydroxychloroquine in diabetic rats is concentration dependent 1. 123, 118-123. 
9. Uzar, E., Ozay, R., Evliyaoglu, O., Aktas, A., Ulkay, M. B., Uyar, M. E., et al., (2012). Hydroxycloroquine-induced oxidative stress on sciatic nerve and muscle tissue of rats.

10. Kakadiya, J., \& Shah, N. (2011). Comparison effect of Pioglitazone and Glimepiride alone on renal function marker in experimentally. 01(03), 72-76.

11. El-batran, S. A., Abdel-salam, O. M. E., Nofal, S. M., \& Baiuomy, A. R. (2006). Effect of rosiglitazone and nateglinide on serum glucose and lipid profile alone or in combination with the biguanide metformin in diabetic rats. 53, 69-74.

12.Nirmala, C. and Puvanakrishnan, R. (1994): Isoproterenol Induced myocardial infarction in rats: functional and biochemical alteration.Med. Sci. Res.,22:575-7.

13.Date, Y., Nakazato, M., Murakami, N., Kojima, M., Kangawa, K., \& Matsukura, S. (2001): Ghrelin acts in the central nervous system to stimulate gastric acid secretion. Biochemical and biophysical research communications, 280(3), 904-907.

14.Burrin, J. M. and Price, C. P. (1985): Measurement of blood glucose. Ann. Clin. Biochem. 22: 327-342.

15. D'Angelo, G., Elmarakby, A. A., Pollock, D. M., \& Stepp, D. W. (2005). Fructose feeding increases insulin resistance but not blood pressure in Sprague-Dawley rats. Hypertension, 46(4), 806-811.

16. Matthews, D. R., Hosker, J. P., Rudenski, A. S., Naylor, B. A., Treacher, D. F., \& Turner, R. C. (1985). Homeostasis model assessment: insulin resistance and $\beta$-cell function from fasting plasma glucose and insulin concentrations in man. Diabetologia, 28(7), 412419.

17. Siedel, J.H.; Schlumberger, S.; Klose, J. and Washlefeld, A.W. (1991): J. Clin. Chem. Clin. Bioch; 19: 838. quoted from Boehringer Mannheim GMBH Diagnostic Manual.

18. Lopes-Virella, M.F.; Stone, P.; Ellis, S. and Colwell, J.A. (1977):Cholesterol determination in high-density lipoproteins separated by three different methods. Clin. chem; 23 (5):882-4.

19.Friedewald,W.T.;Levy,R.I. and Fredrickson, D.S. (1972): Estimation of the concentration of lowdensity lipoprotein cholesterol in plasma, without use of the preparative ultracentrifuge. Clin. Chem; 18: 499-512.

20. Ma, X., Xu, W., Zhang, Z., Liu, N., Yang, J., Wang, M., et al. (2017). Salvianolic acid B ameliorates cognitive deficits through IGF-1/Akt pathway in rats with vascular dementia. Cellular Physiology and Biochemistry, 43(4), 1381-1391.

21.Fischer, A. H., Jacobson, K. A., Rose, J., \& Zeller, R. (2008). Hematoxylin and eosin staining of tissue and cell sections. Cold Spring Harbor Protocols, 2008(5), pdb-prot4986.

22.Patel, R., Shah, P., Deshpande, S(2015):Fructose diet and low dose streptozotocin treatment induces the development of diabetic nephropathy in rats. Orient Pharm Exp Med 15, 305312 (2015).

23.Kale, O.E., Akinpelu, O.B., Bakare, A.A. (2018). Five traditional Nigerian Polyherbal remedies protect against high fructose fed, Streptozotocininduced type 2 diabetes in male Wistar rats. BMC Complement Altern Med 18, 160.

24. Baidya, Arjun, \& Ahmed, R. (2018). Effect of early addition of hydroxychloroquine in type 2 diabetic patients inadequately controlled on metformin and sulfonylurea combination therapy. International Journal of Research in Medical Sciences, 6(8), 1.

25. Wondafrash, D. Z., Desalegn, T. Z., Yimer, E. M., Tsige, A. G., Adamu, B. A., \& Zewdie, K. A. (2020). Review Article Potential Effect of Hydroxychloroquine in Diabetes Mellitus: A Systematic Review on Preclinical and Clinical Trial Studies. 2020.

26. Gaede, P., Lund-Andersen, H., Parving, H.H., Pedersen, O. (2008): Effect of a multifactorial intervention on mortality in type 2 diabetes. $\mathrm{N}$ Engl J Med; 358: 580-91.

27. Chakravorty, S., Purkait, I., Pareek, A., \& Talware, A. (2017). Hydroxychloroquine: Looking into the future. Romanian Journal of Diabetes, 
Nutrition and Metabolic Diseases, 24(4), 369-375.

28. Ahmed, R. (2018). Comparison between the clinical efficacy and safety of hydroxychloroquine and sitagliptin added to inadequately controlled with glimepiride and metformin in Indian patients with type 2 diabetes mellitus: a real-world observational study. EC Endocrinology and Metabolic Research, 3, 147-155.

29. Pareek, A., Chandurkar, N., Thomas, N., Viswanathan, V., Deshpande, A., Gupta, O. P., et al. (2014). Efficacy and safety of hydroxychloroquine in the treatment of type 2 diabetes mellitus: a double blind, randomized comparison with pioglitazone. Current Medical Research and Opinion, 30(7), 1257-1266.

30. Bertrand, L., Horman, S., Beauloye, C., \& Vanoverschelde, J.-L. (2008). Insulin signalling in the heart. Cardiovascular Research, 79(2), 238-248.

31. Jia, G., Whaley-Connell, A., \& Sowers, J. R. (2018). Diabetic cardiomyopathy: a hyperglycaemiaand insulin-resistance-induced heart disease. Diabetologia, 61(1), 21-28.

32. Infante, M., Ricordi, C., \& Fabbri, A. (2020). Antihyperglycemic properties of hydroxychloroquine in patients with diabetes: risks and benefits at the time of COVID-19 pandemic. Journal of diabetes, 12(9), 659-667.

33. Wang, R., Xi, L., \& Kukreja, R. C. (2017). PDE5 inhibitor tadalafil and hydroxychloroquine cotreatment provides synergistic protection against type 2 diabetes and myocardial infarction in mice. Journal of Pharmacology and Experimental Therapeutics, 361(1), 29-38.

34. Hausenloy, D. J., Wynne, A. M., Mocanu, M. M., \& Yellon, D. M. (2013). Glimepiride treatment facilitates ischemic preconditioning in the diabetic heart. Journal of Cardiovascular Pharmacology and Therapeutics, 18(3), 263-269.
35. Zaafan, Mai \& Zaki, Hala \& El-Brairy, Amany ,et al., (2012): Isoprenaline-Induced Myocardial Infarction in Rats: Protective Effects of Hesperidin. Egyptian Journal of Basic and Clinical Pharmacology. 2. 10.11131/2012/101336.

36.Moradi-Arzeloo, M., Farshid, A. A., Tamaddonfard, E., \& Asri-Rezaei, S. (2016). Effects of histidine and vitamin $\mathrm{C}$ on isoproterenolinduced acute myocardial infarction in rats. Veterinary research forum : an international quarterly journal, 7(1), 47-54.

37. 55.Zaki, S. M., Abdalla, I. L., EI Sadik, A. O., Mohamed, E. A., \&Kaooh, S.(2018): Protective Role of N-Acetylcysteine on Isoprenaline-Induced Myocardial Injury: Histological, Immunohistochemical and Morphometric Study. Cardiovascular toxicology, 18(1), 9-23

38.Bourke, L., McCormick, J., Taylor, V., Pericleous, C., Blanchet, B., CostedoatChalumeau, N., et al., (2015). Hydroxychloroquine protects against cardiac ischaemia/reperfusion injury in vivo via enhancement of ERK1/2 phosphorylation. PLoS One, 10(12), e0143771.

39.Hartman, O., Kovanen, P. T., Lehtonen, J., Eklund, K. K., \& Sinisalo, J. (2017). Hydroxychloroquine for the prevention of recurrent cardiovascular events in myocardial infarction patients: rationale and design of the OXI trial. European Heart Journal-Cardiovascular Pharmacotherapy, 3(2), 92-97.

To cite this article: Heba A. EL noury, Ahmed F. Bahriz, Amany N. Ibrahim, Aya M. ElBadrawy, Eman A. Abd El Aziz. Study of possible Cardioprotective Effect of Hydroxychloroquine Compared to Glimepiride and Metformin in Diabetic Rats. BMFJ 2022; 39(academic issue):96-110. 